\title{
Optical and Electrical Studies of CdS Thin Films with thickness variation
}

DOI:

10.1016/j.ijleo.2018.01.045

Document Version

Accepted author manuscript

Link to publication record in Manchester Research Explorer

\section{Citation for published version (APA):}

Mahmoud, W., Ali, J., Zahid, I., Thomas, A., \& UI Haq, A. (2018). Optical and Electrical Studies of CdS Thin Films with thickness variation. OPTIK, 158, 1558-1566. https://doi.org/10.1016/j.ijleo.2018.01.045

\section{Published in:}

OPTIK

\section{Citing this paper}

Please note that where the full-text provided on Manchester Research Explorer is the Author Accepted Manuscript or Proof version this may differ from the final Published version. If citing, it is advised that you check and use the publisher's definitive version.

\section{General rights}

Copyright and moral rights for the publications made accessible in the Research Explorer are retained by the authors and/or other copyright owners and it is a condition of accessing publications that users recognise and abide by the legal requirements associated with these rights.

\section{Takedown policy}

If you believe that this document breaches copyright please refer to the University of Manchester's Takedown Procedures [http://man.ac.uk/04Y6Bo] or contact uml.scholarlycommunications@manchester.ac.uk providing relevant details, so we can investigate your claim.

\section{OPEN ACCESS}




\title{
Optical and Electrical Studies of CdS Thin Films with thickness variation
}

\author{
Waqar Mahmood ${ }^{(1,2),{ }^{*}, \text { Junaid Ali }}{ }^{(3), *}$, Iqra Zahid ${ }^{(4)}$, Andrew Thomas ${ }^{(2),}$ Anwar ul Haq ${ }^{(4)}$ \\ ${ }^{(1)}$ Material Synthesis \& Characterizations (MSC) Laboratory, Department of Physics, Fatima Jinnah Women \\ University, The Mall Rawalpindi, PAKISTAN. \\ ${ }^{(2)}$ The School of Physics and Astronomy, Photon Science Institute, The University of Manchester, Oxford Road \\ Manchester, M13 9PL, UNITED KINGDOM. \\ ${ }^{(3)}$ Department of Physics, COMSATS Institute of Information Technology, Park Road, Islamabad, 45600, \\ PAKISTAN \\ (4) Department of Physics, Govt. Postgraduate College, Satellite Town Rawalpindi, 44000, PAKISTAN \\ *Corresponding Authors'e-mail: junaid_ali@comsats.edu.pk,waqarmahmood@,jwwu.edu.pk
}

Keywords: II-VI thin films, activation energy, optical, electrical, second generation solar cell

Cadmium sulphide (CdS) is the n-type, wide band gap II-VI semiconducting material by offering applications in photovoltaics. Among the range of applications offered by $\mathrm{CdS}$ thin films, it has found application as a window layer in second generation solar cells by creating photon traps, thereby quantum efficiency. Closed space sublimation (CSS) offers a trivial yet effective approach for the synthesis of thin films for solar cell applications at moderate temperatures. CdS thin films of controlled thicknesses were synthesized by CSS technique by varying exposure time. X-rays diffraction data of these thin films revealed polycrystalline nature with a preferred orientation along (002) direction. The scanning electron microscopy (SEM) based morphological studies showed grain size variation with an increase in thickness of deposited thin films in the range of $300-500 \mathrm{~nm}$. The electrical studies revealed high resistivity of the order of $10^{6} \Omega-\mathrm{cm}$. Spectrophotometric studies performed for CdS thin films concluded with the calculation of the optical parameters such as refractive index, absorption coefficient employing the Swanepoel model, and energy band gap of $\sim 2.42 \mathrm{eV}$ using the Tauc relation in addition to thin film thickness confirmation. The variations in thickness affect the structure, surface, optical ${ }^{1}$, electrical properties. 


\section{Introduction}

After initial sparkle of single crystal Silicon (c-Si) based the first generation of solar cells, the second generation also called polycrystalline solar cells have been a key research avenue for solar cell scientists. The latter generation is based on cadmium telluride (CdTe) absorbent material, a low cost, II-VI compound semiconductor material ${ }^{2}$. The compound semiconductors such as cadmium sulphide (CdS), zinc telluride ( $\mathrm{ZnTe}$ ), zinc selenide ( $\mathrm{ZnSe}$ ) are large band gap materials that have found applications in Light emitting diodes (LED) ${ }^{3}$, photo catalysis ${ }^{4}$, detectors $^{5}$ and photovoltaics ${ }^{1,6,7}$. Efficient thin films based photonic devices can be fabricated by employing a various thin film fabrication technologies ${ }^{8,9} . \mathrm{CdS}$ is an n-type potential window layer material in $\mathrm{CdTe}^{7}$ based solar cells, with energy band gap of $2.42 \mathrm{eV}^{10}$. Many techniques have been used to synthesize CdS thin films including chemical vapour deposition (CVD) ${ }^{11}$ and physical vapour deposition (PVD), chemical bath deposition (CBD) ${ }^{12}$, thermal evaporation ${ }^{13}$, pulsed laser ${ }^{14}$ and close spaced sublimation (CSS) techniques ${ }^{15}$. Encouraging results have been attained by using CSS technique for the second generation based solar cells ${ }^{16}$. CSS is simple, inexpensive thin film deposition technique, famous for its efficient use of material, small sourcesubstrate separation and high throughput under low vacuum conditions ${ }^{17}$.

The heterojunction between CdS (window layer) and CdTe (absorbent layer), constitutes a p-n junction in the second-generation solar cell. For CSS deposited CdS thin films, the c-axes are perpendicular to the substrate along with the vertical growth of crystallite in columnar form. This effect allows fewer grain boundaries and therefore can control the flow of charge carriers parallel to the junction. The necessary window layer characteristics include high transparency with low resistivity, ${ }^{9,17}$ so that incident radiation can transmit through the window layer arrive at absorbent layer with minimum losses. The optical absorption coefficient must be less than the absorbent layer i.e., $\sim 10^{5} \mathrm{~cm}^{-1}$. A very thin window layer with a thickness in nanometers range may thus help overcome the absorption losses and enhance the open circuit voltage. Energy band gap of window layer should be larger than the absorbent layer with minimum lattice mismatch ${ }^{2}$. Since photocurrent is not generated in the window layer, so the direct bandgap material can be used as a window layer. Fabrication techniques and the growth parameters play a vital role to control the thickness ${ }^{17,18}$. Here we present on the influence of thickness on structural and morphological characteristics alongside electrical and optical properties of CSS deposited CdS 
thin films. The structure of the as-deposited transparent and yellowish CdS thin films were studied by X-rays diffractometer with $\mathrm{Cu} \mathrm{k- \alpha}$ line at a wavelength of $1.5406 \AA$. The surface morphology was studied through scanning electron microscope (SEM) whereas optical properties including refractive index, absorption coefficient, energy band gap and consequently thickness of thin films by spectrophotometer. The electrical properties such as conductivity, resistivity and mobility were studied by Hall measurement apparatus. The correlation between structure, surface, optical and electrical properties were studied for the potential use of CdS thin film as a window layer in CdTe based solar cell.

\section{Experimental}

Cadmium sulphide (CdS) powder (99.99\%-Aldrich Company) was used as a source material placed in a graphite boat. Soda-lime glass slides $(7.5 \mathrm{~cm} \times 0.5 \mathrm{~cm} \times 2.5 \mathrm{~cm})$ were used as substrates for deposition of thin films. The optimized source-substrate separation was $5 \mathrm{~mm}$ for superior quality films. Halogen lamp L1 (L2) power rating $1000 \mathrm{~W}(500 \mathrm{~W})$ was used for direct heating of source (substrate) to the optimized temperature of $600 \pm 5{ }^{\circ} \mathrm{C}\left(450 \pm 5{ }^{\circ} \mathrm{C}\right)$. The temperatures at both source and substrate were monitored by K-type thermocouples. Both lamps were switched $\mathrm{ON}$ only after rotary and diffusion pumps evacuated the chamber to $10^{-4}$ mbar. The variation of deposition time from 60 to 420 seconds controlled the thickness of thin films after attaining the optimized temperature. After this time interval, the lamp heating source was switched off and however the other lamp heating substrate was used to anneal the deposited thin films. This annealing at vacuum, ensured rearrangement of thin film constituents in a uniform manner, without contamination on exposure to air, and hence may reduce the resistivity and enhance the crystal structure and optical properties ${ }^{2,19}$. Eventually, this lamp too was switched OFF so that chamber could cool down to the room temperature (RT). X-ray diffraction (XRD) analyses were carried out using X'PERT Pro PANanalytic diffraction machine operated at 40 $\mathrm{keV}$ to $30 \mathrm{~mA}$. All morphological aspects are characterized by scanning electron microscopy (SEM) providing basic information about particle size, shape and surface features. Optical properties were analyzed using spectrophotometer (Perkin Elmer Lambda 950) in UV-VIS-NIR range using UV-Win Lab software. All electrical measurements were carried out at room temperature (RT). Four-point probe technique was adopted to study the electrical behaviour of as-deposited CdS thin films fabricated by CSS method. Fourier-transform-infrared (FTIR) 
studies were conducted to investigate the bending and stretching of functional groups present in the materials.

\section{Results and Discussion}

\section{Structural study}

Structure of $\mathrm{CdS}$ thin films depends on deposition techniques and its parameters. The crystal structure and crystalline quality of as-deposited CdS thin films were analyzed using nondestructive technique X-ray diffraction (XRD) with diffraction angle ranging from $20^{\circ}$ to $60^{\circ}$. XRD peaks have a broad profile which confirms the presence of nanocrystallites, lattice defects and microstrain etc. The background in CdS- 01 and CdS- 05 of XRD patterns were may be due to amorphous phases in $\mathrm{CdS}$ thin films or by amorphous nature of glass substrate. In other CdS thin films, this effect was not so dominant due to the strong interaction between the films and the substrate. The as-deposited $\mathrm{CdS}$ thin films showed polycrystalline behaviour. XRD analysis exhibits mixed hexagonal and cubic phases of $\mathrm{CdS}$, the planes observed by the scattering from (002), (101), (102), (110) and (103). The broadened peaks are indicating that the size of CdS is in nano-ranges. The XRD pattern showed intense peak is of (002) according to the corresponding orientation of $\mathrm{CdS}$ thin films at $26.56^{\circ}$. The lowest free energy is responsible for the growth of (002) parallel to the substrate surface. The peaks were matched manually with the reference card of ICDD 00-001-0780. The preferred orientation (002) corresponds to wurtzite hexagonal structure in CdS thin films. The other reflection peaks (220) were matched with the reference card ICDD 00-001-0647 showed the cubic zinc blende system in CdS thin films. The variation in the deposition time of films allows more atoms to reach the substrate and thus increase thin film thickness. During a typical thin film growth process, the formation of new crystallites and the increase in grain size of already nucleated grains occur side by side controlled by deposition temperature. If the rate of formation of new crystallites outpaced the rate at which already nucleated grains grow, the diffraction intensities would decrease as observed in Fig. 1. Consequently, the FWHM decreased with dwell time, due to the formation of new smaller grains on the surface of larger grains. Crystallite size D was estimated using Scherrer's formula 9,20-23 


$$
D=\frac{k \lambda}{\beta \cos \theta}
$$

Here, $k$ is machine constant was 0.9 , and wavelength $(\lambda)$ used $1.5406 \AA$, $\theta$ is the Bragg's angle (in radians), and $\beta$ is a full-width half maximum of XRD spectral peaks. The calculated sizes of crystallites were in the range $24-32 \mathrm{~nm}$. It was observed that crystallite size changed with the increase in the thickness of the CdS thin films.

It is considered that more atoms can move a relatively longer distance and thermally occupy lattice site for the grain. Dislocation density, $\rho$ is a measure of defects in the crystal ${ }^{24}$. It was in range $(0.98-1.68) \times 10^{15}$ lines $m^{-2}$, when calculated using Scherrer's formula, $\rho=1 / D^{2}$. The strain $(\epsilon)$ within thin film ${ }^{7}$ given by relation $\epsilon=\frac{\beta \cos \theta}{4}$ varied from $1.08 \times 10^{-3}$ to $1.42 \times 10^{-3}$. FWHM of the peaks decreased with increase in thicknesses of CdS thin films, thus confirming inverse relation between $D$ and crystallinity and hence it is concluded that increase in thickness improved crystallinity. As the thickness increased, the crystallite size changed, so dislocation density and strain decreases ${ }^{17}$.The (002) peak shifts toward higher angular value confirming the change of crystallite size with thickness changes also related to stacking fault probability $\left(\alpha_{s f}\right)^{25}$.

$$
\alpha_{s f}=\frac{2 \pi^{2} \Delta(2 \theta)}{45 \sqrt{3} \tan \theta}
$$

(Error! Bookmark not

defined.)

The probability of stacking fault decreased with increase in thickness of CdS thin films. The stress and dislocation density have large values for less thickness and has a higher mismatch between the film and the substrate. The increase in thickness is one of the reasons for the decrease in stress and dislocation density of CdS thin films.

This effect confirms the saturation of crystallite growth by releasing the misfit strain between the substrate and the CdS thin films with an increase in thickness and finally stacking fault probability decreases. The change in thickness also showed that shift in peaks of CdS which caused a decrease in lattice constant which shows substitution effects. Thickness effects can also be seen through the peak intensities shown in Fig. 1. The ratio of preferred orientation peak to 
$(101) /(002),(102) /(002),(110) /(002)$ and $(103) /(002)$ shows the reorientation of the planes. The crystal structure and the variation in lattice constant related to the variation in thickness of $\mathrm{CdS}$ thin films. Since the value of $c / a$ approached 1.633 with an increase in thickness, it can be inferred tensile strain decreased along [002] directions parallel to c- axis inversely with a thickness of thin film.

Texture coefficient (TC) is another crucial factor which could influence the physical properties of CdS thin films. It measures the degree of orientation of each peak to the randomly oriented sample.

$$
\text { T.C. }=\frac{I(h k l)}{I o(h k l)}\left\{\begin{array}{l}
1 \\
N
\end{array} \sum_{i=0}^{n} \frac{I(h k l)}{I o(h k l)}\right\}^{-1}
$$

(Error! Bookmark not defined.)

Here $I(h k l)$ and $I_{o}(h k l)$ are the diffraction intensity of observed and standard samples respectively and $\mathrm{N}$ denotes the number of reflected peaks. Since T.C. decreased proportionally from 3.31-0.37 with the thickness, it confirms the improvement in crystallinity of film structure with processing time. Increase in growth time influences the texture coefficient on the surface of crystallites of the CdS thin films. On a concluding note, it is observed that increase in thickness has an inverse relation with strain and dislocation density and T.C. and crystallite size directly influenced by it. These structural parameters may enhance the physical properties of as-deposited CdS thin films.

\section{Surface analysis}

The study of surface morphology of thin film provides useful and valuable information on shape, size and particle arrangements. The SEM micrographs show the surface morphology of asdeposited CdS thin films as shown in Fig. 2. The images clearly show the irregular shapes, nonuniform grain sizes and voids in the as-deposited CdS thin films also the surface smoothness changed as thickness changed. Grain sizes of as-deposited CdS thin films depend strongly depend upon thickness. The average grain size of as-deposited CdS thin films is $50 \mathrm{~nm}$. In principle, after deposition for various time durations, the atoms diffuse into $\mathrm{CdS}$ and organize themselves for bigger grains. The coalescences play a vital role in CdS thin films when the thickness is increased, small grains coalesce with each other when due to ad-atoms ${ }^{26-29}$. These 
atoms may displace from interstitially or $\mathrm{Cd}$ and $\mathrm{S}$ atoms interchange their positions which is also changes the composition of as-deposited $\mathrm{CdS}$ thin films. One possibility is the selfinterstitial on the CdS lattice. The increase in thickness is responsible for re-crystallization of grains, which promotes the reorientation of the overall microstructure ${ }^{27-30}$. SEM micrographs clearly indicate a remarkable increase in grain sizes of as-deposited $\mathrm{CdS}$ thin films. The change in the thickness also indicates the improvement in crystallinity, the stress produced due to grains and defects resulting in the increase in grain sizes ${ }^{30}$.

The SEM image of the as-deposited CdS thin film also demonstrates roughness ${ }^{26}$, which was reduced as the thickness of as-deposited CdS thin film increased. The grains present in asdeposited CdS thin film also became irregular and diverse in sizes as the thickness changes. The increase in thickness also facilitated in triggering the process of coalescence. The recrystallization of grain's growth in semiconductors are reported comprehensively.

\section{Optical study}

Investigations of optical properties like energy band gap, refractive index and transmission are of much significance in case of optoelectronics applications. The transmission spectra of asdeposited CdS thin films shown in Fig. 3 show strong absorption edge at $\sim 500 \mathrm{~nm}$. The oscillations are due to the constructive and destructive interference, the maxima related to the constructive interference and the minima is due to destructive interference. The CdS thin films have transmissions in the range of 60 to $85 \%$ invisible region. Since UV region consists of greater energy as compared to the energy band gap of $\mathrm{CdS}$, hence, it is thoroughly absorbed. The NIR and visible region, however, are entirely transparent. The as-deposited CdS thin films are well-thought-out for this reason, acts as a window material for visible as well as the infrared region.

Transmission spectrums in Fig. 3 indicate the effects of thickness on optical properties like energy band gap, absorption coefficient and refractive index etc. These properties were measured using transmittance data and fitting the transmittance curve $e^{24,31}$ by Eq

$$
T=\frac{A x}{B-C x \cos (\varphi)+D x^{2}}
$$


The parameters $A=16 n^{2} s, \quad B=(n+1)^{2}\left(n+s^{2}\right), \quad C=2\left(n^{2}-s^{2}\right)\left(n^{2}-1\right), \quad D=$ $\left(n-s^{2}\right)(n-1)^{3}, \Phi=4 \pi n d / \lambda, x=\exp (-d \alpha), k=\alpha \lambda / 4 \pi$. Here $s$ and $n$ are the refractive indices of glass substrate and the film respectively. Absorption of the film in transparent region could be due to the scattering of light, defect absorption, multi-phonon absorption, or Urbach tail. Absorption process reliant on the wavelength is complex; hence, if the absorption is minute around phonon energy far from any absorption line, Taylor series is used. ' $\alpha$ ' can be expressed using the relation $\alpha=c+\frac{f}{\lambda}+\frac{g}{\lambda^{2}}+\ldots$, here, $f$ and $g$ are constants. The calculation of $\alpha$ in the region of high absorption could be done by using $n$ and $d$ by curve fitting. The region of high and medium region of absorption precise solution for $x$ in Eq. (5) gives the value of $\alpha$ at every wavelength.

$$
x=\frac{\left(C^{\prime}+A / T\right)-\left(\left(C^{\prime}+A / T\right)^{2}-4 B D\right)^{1 / 2}}{2 D}
$$

Here, $C^{\prime}=\mathrm{C} \cos \phi$ and $\alpha=-\ln (x) / d$.

Increase in anneal time of CdS showed variations in transmission, refractive index and energy band gap. Energy band gap is calculated ${ }^{20,32-36}$ using Eq. (7):

$$
\alpha h v=A\left(h v-E_{g}\right)^{N / 2}
$$

$\alpha$ is measured using the well-known relation: $\alpha=-\frac{1}{d} \ln (T)$. Here, $d$ and $T$ are thickness and the transmittance respectively of the CdS thin films shown in Fig. 4. Thickness was calculated by using Eq. (4). Thickness of the CdS thin film can be calculated using relation:

$$
d=\frac{\lambda_{\max } \lambda_{\min }}{4 n\left(\lambda_{\max }-\lambda_{\min }\right)}
$$

Where, $d$ : thickness of CdS thin film, $\lambda_{\min }$ : minimum and $\lambda_{\text {Max }}$ : the maximum value of the wavelength extracted from the transmission spectra. A significant decrease in transmission is demonstrated after an increase in thickness Fig. 5.

The value of thickness varies from 270 to $680 \mathrm{~nm}$ as deposition time increased. The band gap values were 2.38 to $2.45 \mathrm{eV}$ as shown in Fig. 4. It is observed that by increasing thickness, the value of band gap shortly decreased. The decrease in transmission of CdS thin film has been 
observed from $40 \%$ to $80 \%$ by increasing thickness. The values of refractive index changes from 2.2 to 3.47 as thickness increased as shown in Fig. 5. The transmission of CdS thin film

gradually decreased because of increasing refractive index. The variation in energy band gap and the refractive index is the removal of defects states from forbidden energy gap with an increase in thickness as shown in Fig. 5. The maximum value of energy band gap and the refractive index suggested that thickness of CdS thin film was good for window layer further increase in thickness produced structural disordered and defects states in CdS thin films.

\section{Electrical study}

The conductivity in a semiconductor depends upon temperature and discussed by different models based on mobility edge and density of states. The electronic conduction in semiconductors is mediated by three mechanisms for different ranges of temperature ${ }^{37}$,

- Transport the carriers excited into non-localized states at valance or conduction band.

- Transport the carriers excited into localized states at the hopping and bad edge.

- When there are finite density states from the carrier with energy near $E_{f}$ which can hop between localized states.

A major concern in electrical measurements is mobility; resistivity, carrier concentration, types of semiconductors. The electrical properties e.g. resistivity, carrier concentrations of as-deposited CdS thin films were calculated at room temperature. The n-type conductivity was confirmed by Hall measurement. The thickness affects the resistivity of as-deposited CdS thin films shown in Fig. 6. The resistivity of as-deposited CdS thin films was $\sim 10^{5} \Omega-\mathrm{cm}$. As the thickness increases, resistivity decreases, and consequently the increase of carrier concentration in CdS films. The decrease in resistivity with an increase in thickness might be due to the less number of defects and ordered structure of $\mathrm{CdS}$ thin films. The activation energy is a measure of trapping levels and hence the decrease showed the redistribution of traps. A slight change in activation energies were observed for the thin films in range from $5.24 \pm 0.24-3.2 \pm 0.11 \mathrm{eV}$. The change in activation energy is due to the removal of defect states which are present in the CdS thin films. The slopes of conductivity v/s temperature have been shown as shown in Fig. 7. It is considered 
that the activation energy related to donor levels which are associated with the surface states or shallow traps created by Sulphur vacancies in CdS thin films.

\section{Composition analysis}

FTIR measurements have been done to understand the defects and impurity contents and compositional structure of $\mathrm{CdS}$ thin films. The FTIR transmission spectra for CdS films in Fig. 8 were acquired in the wave number ranging from 400 to $4000 \mathrm{~cm}^{-1}$. The transmission bands at $730.6,741.8,742.2$ and $762.7 \mathrm{~cm}^{-1}$ were assigned to the $\mathrm{CdS}{ }^{38}$ stretching frequency. The other major peaks at $872.9,2850.2$ and $2919.1 \mathrm{~cm}^{-1}$ correspond to $\mathrm{C}-\mathrm{H}$ bending, $\mathrm{C}-\mathrm{H}$ fingerprint region (1716.4 and $1733.8 \mathrm{~cm}^{-1}$ ). The broad absorption band at $3521.2 \mathrm{~cm}^{-1}$ is due to the $\mathrm{O}-\mathrm{H}$ stretching vibrations of water $\left(\mathrm{H}_{2} \mathrm{O}\right)$ molecules $^{38}$, A strong band at 1563.3 due to $\mathrm{C}=\mathrm{C}$ stretching band is also noted, C-H Bending mode (1423.0).

\section{Conclusions}

The XRD patterns showed the polycrystalline behaviour of as-deposited thin films with preferred orientation was [002] direction. A shift was observed in-plane peaks as the thickness increased result the increase in crystallite size of the as-deposited CdS thin film. The SEM micrographs showed the smooth, non-uniform grain sizes and a rough surface having voids in it. The roughness is important for light trapping through window layer and the voids correspond the surface defects, as the thickness increases the voids decreases confirming the decrease in surface defects. The optical energy band gap decreases as the thickness increases also transmission decreases, so more thick films are not suitable for window layer. The as-deposited CdS thin films were highly resistive, the thickness also showed a decrease in resistivity of the as-deposited CdS thin films. These results may confirm that the variations in thickness strongly affect the physical properties of as-deposited CdS thin films used as a window layer.

\section{Acknowledgements}

This work was supported by the Higher education commission of Pakistan (HEC) grant funded by the Pakistan government (SRGP \# 21-1128/SRGP/R\&D/HEC/2016) and (SRGP\#211387/SRGP/R\&D/HEC/2016) 


\section{References}

1. Khan MJI, Usmani MN, Kanwal Z, Akhtar P. Novel substitutional effects on optical properties of Cds:Co system (A theoretical study). Opt - Int J Light Electron Opt. 2018;156:817-824. doi:10.1016/j.ijleo.2017.12.041.

2. Ferekides CS, Marinskiy D, Viswanathan V, et al. High efficiency CSS CdTe solar cells. Thin Solid Films. 2000;361:520-526. doi:10.1016/S0040-6090(99)00824-X.

3. Eskandari P, Kazemi F, Azizian-Kalandaragh Y. Convenient preparation of CdS nanostructures as a highly efficient photocatalyst under blue LED and solar light irradiation. Sep Purif Technol. 2013;120:180-185. doi:10.1016/j.seppur.2013.09.039.

4. Tsai K-A, Hsu Y-J. Graphene quantum dots mediated charge transfer of CdSe nanocrystals for enhancing photoelectrochemical hydrogen production. Appl Catal B Environ. 2015;164:271-278. doi:10.1016/j.apcatb.2014.09.034.

5. Spirito D, Kudera S, Miseikis V, Giansante C, Coletti C, Krahne R. UV Light Detection from CdS Nanocrystal Sensitized Graphene Photodetectors at kHz Frequencies. J Phys Chem C. 2015;119(42):23859-23864. doi:10.1021/acs.jpcc.5b07895.

6. Bao Z, Liu L, Yang X, et al. Synthesis and characterization of novel oxygenated CdSe window layer for CdTe thin film solar cells. Mater Sci Semicond Process. 2017;63:12-17. doi:10.1016/j.mssp.2017.01.003.

7. Shah NA, Mahmood W. Physical properties of sublimated zinc telluride thin films for solar cell applications. Thin Solid Films. 2013;544:307-312. doi:10.1016/j.tsf.2013.03.088.

8. Zubair M, Mustafa M, Lee K, Yoon C, Doh YH, Choi KH. Fabrication of CdSe/ZnS quantum dots thin film by electrohydrodynamics atomization technique for solution based flexible hybrid OLED application. Chem Eng J. 2014;253(2014):325-331. doi:10.1016/j.cej.2014.05.067. 
9. Mahmood W, Shah NA. CdZnS thin films sublimated by closed space using mechanical mixing: A new approach. In: Optical Materials. Vol 36. ; 2014:1449-1453. doi:10.1016/j.optmat.2013.09.003.

10. Kumar S, Sharma P, Sharma V. CdS nanofilms: Synthesis and the role of annealing on structural and optical properties. J Appl Phys. 2012;111(4):43519. doi:10.1063/1.3688042.

11. Ferrá-González SR, Berman-Mendoza D, García-Gutiérrez R, et al. Optical and structural properties of $\mathrm{CdS}$ thin films grown by chemical bath deposition doped with $\mathrm{Ag}$ by ion exchange. Opt - Int J Light Electron Opt. 2014;125(4):1533-1536. doi:10.1016/j.ijleo.2013.08.035.

12. Vigil-Galán $\mathrm{O}$, Courel $\mathrm{M}$, Andrade-Arvizu JA, et al. Processing pathways of $\mathrm{Cu} 2 \mathrm{Zn}(\mathrm{SnGe}) \mathrm{Se} 4$ based solar cells: The role of CdS buffer layer. Mater Sci Semicond Process. 2017;67:14-19. doi:10.1016/j.mssp.2017.05.003.

13. Hegde SS, Kunjomana AG, Prashantha M, Kumar C, Ramesh K. Photovoltaic structures using thermally evaporated SnS and CdS thin films. Thin Solid Films. 2013;545:543-547. doi:10.1016/j.tsf.2013.08.078.

14. Kumar P, Saxena N, Gupta V, Gao K, Singh F, Agarwal A. Effect of swift heavy ions on pulsed laser deposited Ag doped CdS nanocrystalline thin films. Adv Sci Lett. 2014;20(56):977-983. doi:10.1166/asl.2014.5456.

15. Butt S, Shah NA, Nazir A, Ali Z, Maqsood A. Influence of film thickness and In-doping on physical properties of CdS thin films. J Alloys Compd. 2014;587:582-587. doi:10.1016/j.jallcom.2013.10.221.

16. Britt J, Ferekides C. Thin-film CdS/CdTe solar cell with $15.8 \%$ efficiency. Appl Phys Lett. 1993;62(22):2851-2852. doi:10.1063/1.109629.

17. Mahmood W, Shah NA. Study of cadmium sulfide thin films as a window layers. AIP Conf Proc. 2012;1476:178-182. doi:10.1063/1.4751590. 
18. Borse SV, Chavhan SD, Sharma R. Growth, structural and optical properties of Cd1-xZnxS alloy thin films grown by solution growth technique (SGT). $J$ Alloys Compd. 2007;436(1-2):407-414. doi:10.1016/j.jallcom.2006.11.009.

19. Chopra KL, Das SR. Why Thin Film Solar Cells? In: Chopra KL, Das SR, eds. Thin Film Solar Cells. Boston, MA: Springer US; 1983:1-18. doi:10.1007/978-1-4899-0418-8_1.

20. Siddiqui GUD, Ali J, Doh Y-HH, Choi KH. Fabrication of zinc stannate based all-printed resistive switching device. Mater Lett. 2016;166:311-316. doi:10.1016/j.matlet.2015.12.045.

21. Choi KH, Ali J, Na K-H. Fabrication of graphene-nanoflake/poly(4-vinylphenol) polymer nanocomposite thin film by electrohydrodynamic atomization and its application as flexible resistive switching device. Phys B Condens Matter. 2015;475:148-155. doi:10.1016/j.physb.2015.07.028.

22. Choi KH, Ali J, Doh YH. Exploring resistive switching in poly(4-vinylphenol)-graphene nano-composite films. Jpn J Appl Phys. 2015;54(3):35103. doi:10.7567/JJAP.54.035103.

23. Ali J, Rehman MM, Siddiqui G, Aziz S, Choi KH. Printing an ITO-free flexible poly (4vinylphenol) resistive switching device. Phys B Condens Matter. 2017. https://authors.elsevier.com/tracking/article/details.do?aid=310625\&jid=PHYSB\&surnam $\mathrm{e}=$ Ali.

24. Mahmood W, Shah NA, Akram S, Mehboob U, Malik US, Sharaf MU. Investigation of substrate temperature effects on physical properties of ZnTe thin films by close spaced sublimation technique. Chalcogenide Lett. 2013;10(8):273-281.

25. Soleimanian V, Saeedi M, Mokhtari A. The influence of heat treatment on the crystallite size, dislocation density, stacking faults probability and optical band gap of nanostructured cadmium sulfide films. Mater Sci Semicond Process. 2015;30:118-127. doi:10.1016/j.mssp.2014.09.033.

26. Tariq GH, Anis-ur-Rehman M. Characterization of Physical Properties of Thermally 
Evaporated Doped CdS Thin Films for Photovoltaics. Key Eng Mater. 2012;510-511:156162. doi:10.4028/www.scientific.net/KEM.510-511.156.

27. Moualkia H, Hariech S, Aida MS. Structural and optical properties of CdS thin films grown by chemical bath deposition. Thin Solid Films. 2009;518(4):1259-1262. doi:10.1016/j.tsf.2009.04.067.

28. Shah NA, Sagar RR, Mahmood W, Syed WAA. Cu-doping effects on the physical properties of cadmium sulfide thin films. $J$ Alloys Compd. 2012;512(1):185-189. doi:10.1016/j.jallcom.2011.09.060.

29. Mendoza-Pérez R, Sastre-Hernández J, Contreras-Puente G, Vigil-Galán O. CdTe solar cell degradation studies with the use of CdS as the window material. Sol Energy Mater Sol Cells. 2009;93(1):79-84. doi:10.1016/j.solmat.2008.09.016.

30. Hu J, Odom TW, Lieber CM. Chemistry and physics in one dimension: Synthesis and properties of nanowires and nanotubes. Acc Chem Res. 1999;32(5):435-445. doi:10.1021/ar9700365.

31. Shah NA, Mahmood W. Physical properties of sublimated zinc telluride thin films for solar cell applications. Thin Solid Films. 2013;544:307-312. doi:10.1016/j.tsf.2013.03.088.

32. Ali J, Siddiqui G, Yang YJ, Lee KT, Um K, Choi KH. Direct synthesis of graphene quantum dots from multilayer graphene flakes through grinding assisted co-solvent ultrasonication for all-printed resistive switching arrays. RSC Adv. 2016;6(6):5068-5078. doi:10.1039/C5RA21699K.

33. Ali J, Siddiqui GU, Choi KH, Jang Y, Lee K. Fabrication of blue luminescent MoS 2 quantum dots by wet grinding assisted co-solvent sonication. J Lumin. 2016;169:342-347. doi:10.1016/j.jlumin.2015.09.028.

34. Mahmood W, Thomas A, Haq A ul, Shah NA, Nasir MF. Reduced electrical performance of $\mathrm{Zn}$ enriched $\mathrm{ZnTe}$ nanoinclusion semiconductors thin films for buffer layer in solar 
cells. J Phys D Appl Phys. 2017;50(25):255503. doi:10.1088/1361-6463/aa7157.

35. Mahmood W, Shah NA. Effects of metal doping on the physical properties of ZnTe thin films. Curr Appl Phys. 2014;14(3):282-286. doi:10.1016/j.cap.2013.11.021.

36. Mahmood W, Shah NA. CdZnS thin films sublimated by closed space using mechanical mixing: A new approach. In: Optical Materials. Vol 36. ; 2014:1449-1453. doi:10.1016/j.optmat.2013.09.003.

37. Ali A, Abbas Shah N, Maqsood A. Characterization of cadmium telluride thin films fabricated by two-source evaporation technique and $\mathrm{Ag}$ doping by ion exchange process. Solid State Electron. 2008;52(2):205-210. doi:10.1016/j.sse.2007.08.016.

38. Aksay S, Polat M, Özer T, Köse S, Gürbüz G. Investigations on structural, vibrational, morphological and optical properties of $\mathrm{CdS}$ and $\mathrm{CdS} / \mathrm{Co}$ films by ultrasonic spray pyrolysis. Appl Surf Sci. 2011;257(23):10072-10077. doi:10.1016/j.apsusc.2011.06.142. 


\section{List of Figures}

Figure $1 \mathrm{XRD}$ patterns of as-deposited CdS thin films of different thicknesses ........................... 2

Figure 2 SEM images of as deposited CdS thin films grown at different dwell times.................. 2

Figure 3 Transmission spectra of as-deposited CdS thin films were used to estimate the variation

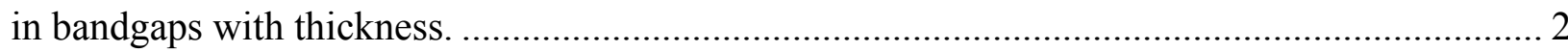

Figure 4 Energy band gaps of As-deposited CdS thin films show an increase with thickness

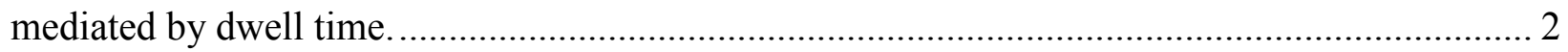

Figure 5 Variation of refractive index and energy band gap vs thickness .................................. 2

Figure 6 The resistivity and mobility of as grown thin films varied with increase in their thicknesses. Beyond a thickness of $500 \mathrm{~nm}$ both the resistivity and mobility changed $\sim 5$ and 100

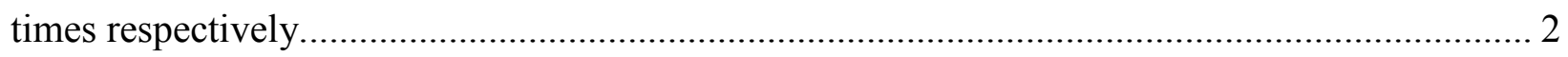

Figure 7 Arrhenius plot of thermal activation energy for as deposited CdS thin films at different dwell times. Activation energies change slightly with growth conditions 2

Figure 8 FT-IR Spectra of as-deposited CdS thin films 2 


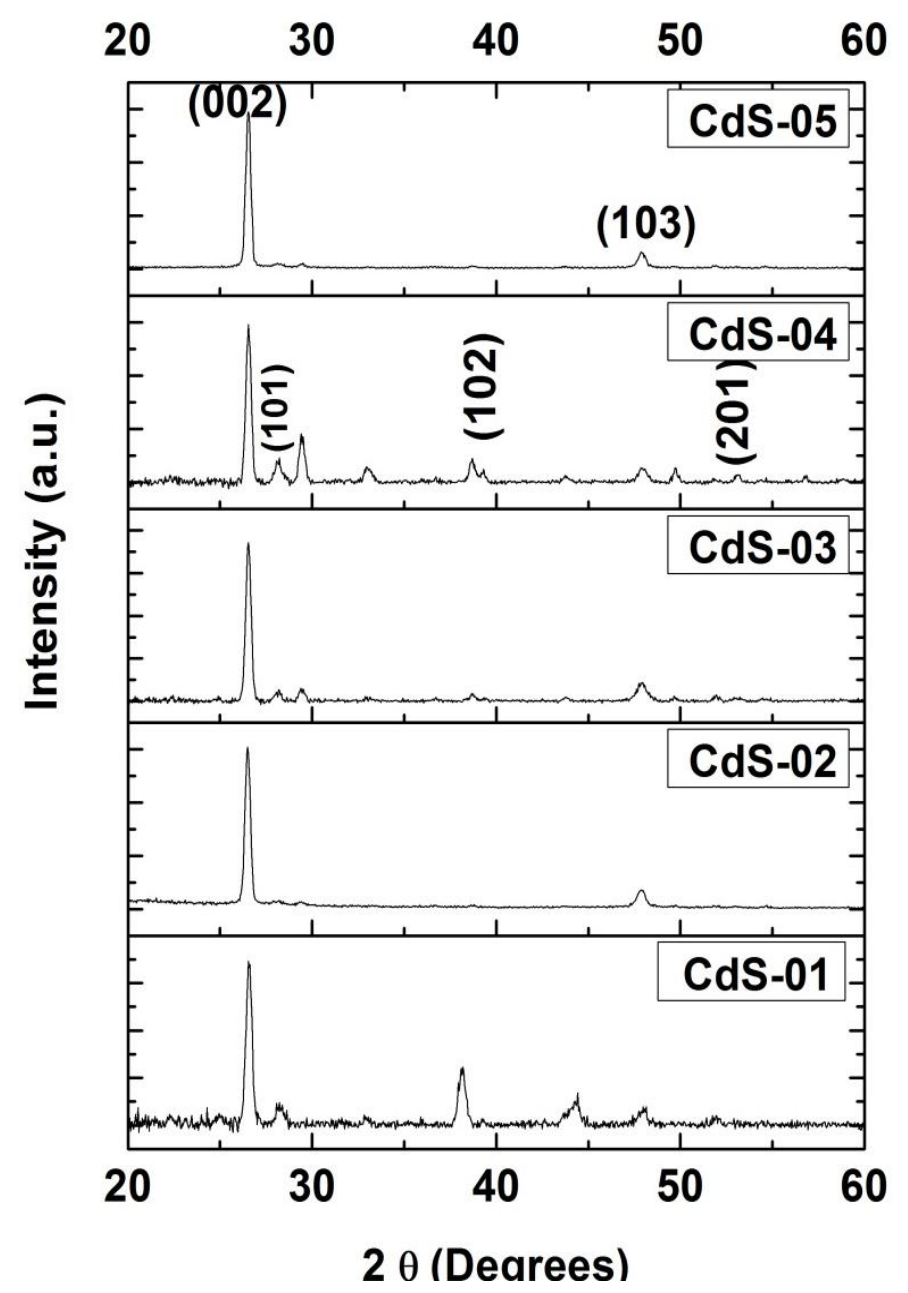

Figure 1 XRD patterns of as-deposited CdS thin films of different thicknesses 

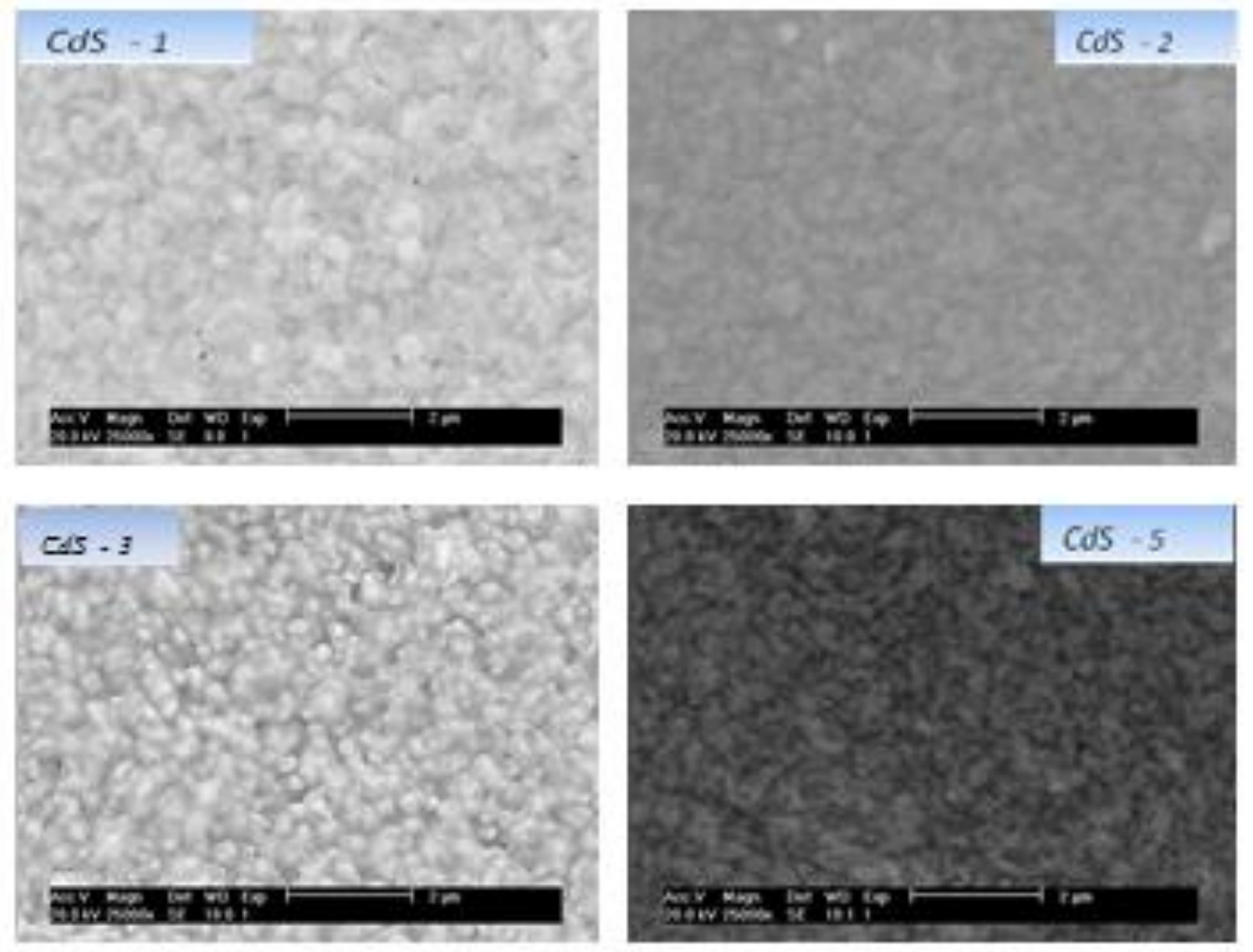

Figure 2 SEM images of as deposited CdS thin films grown at different dwell times. 


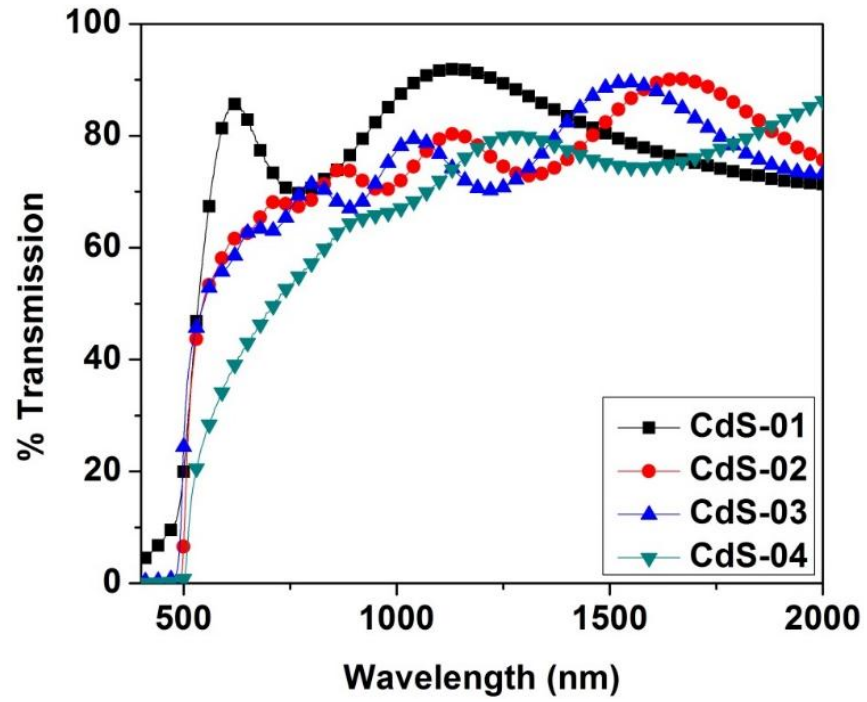

Figure 3 Transmission spectra of as-deposited CdS thin films were used to estimate the variation in bandgaps with thickness. 

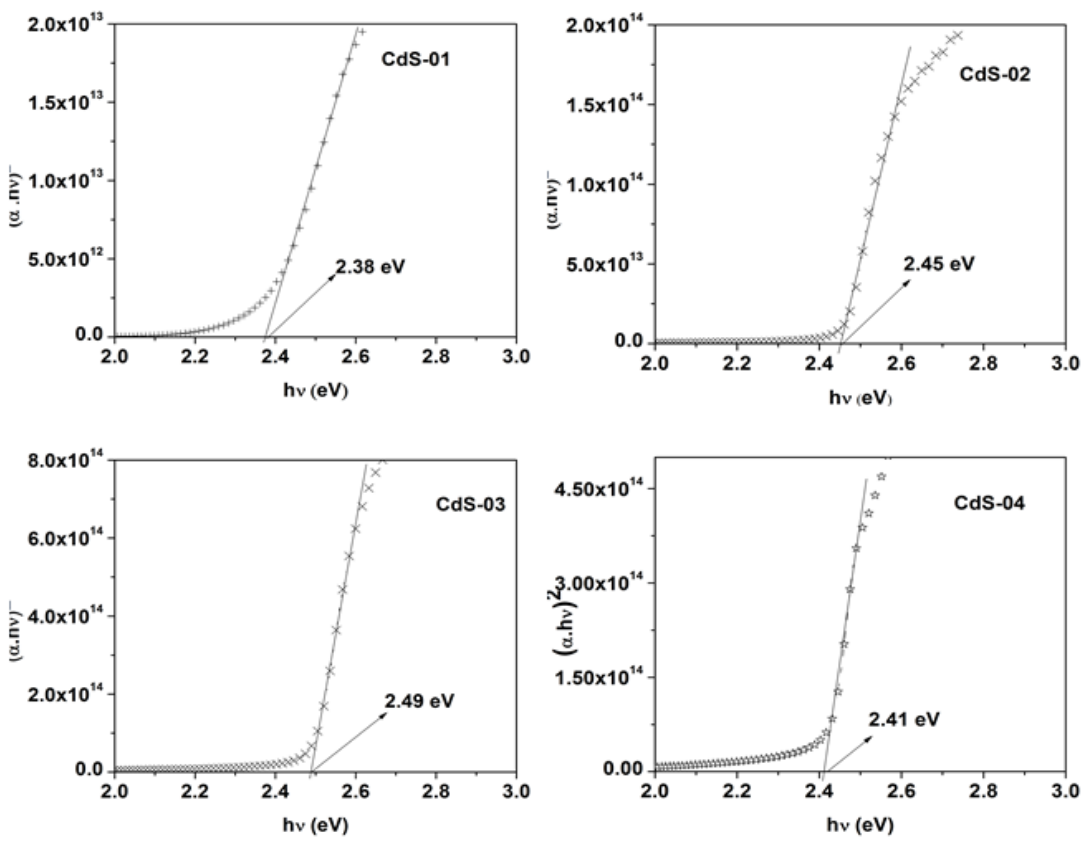

Figure 4 Energy band gaps of As-deposited CdS thin films show an increase with thickness mediated by dwell time. 


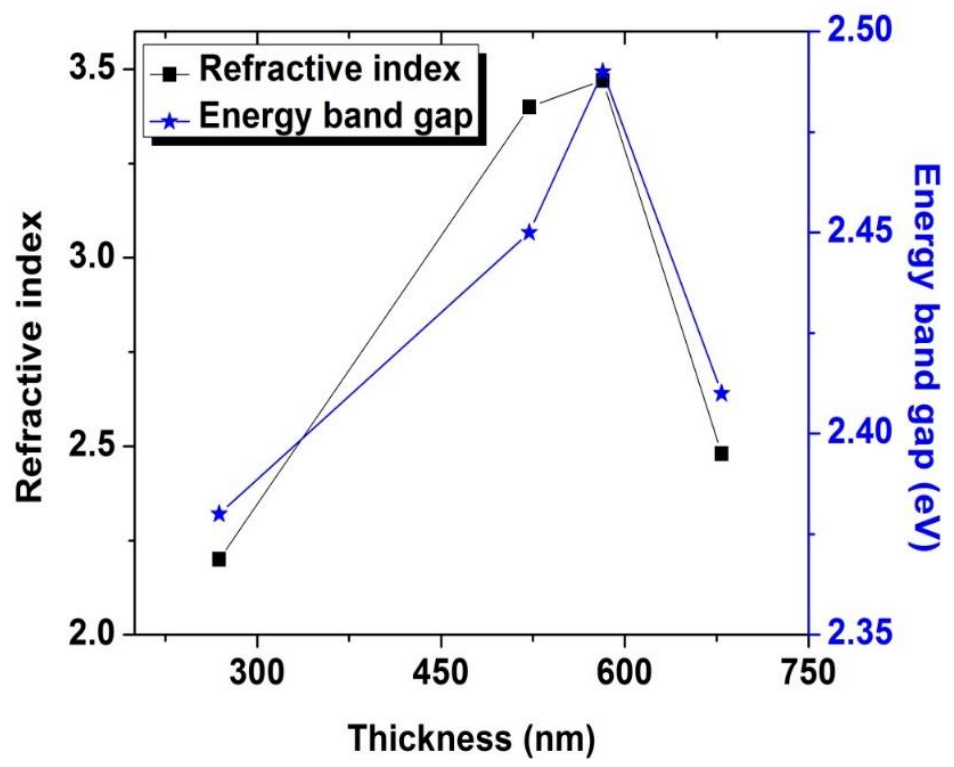

Figure 5 Variation of refractive index and energy band gap vs thickness 


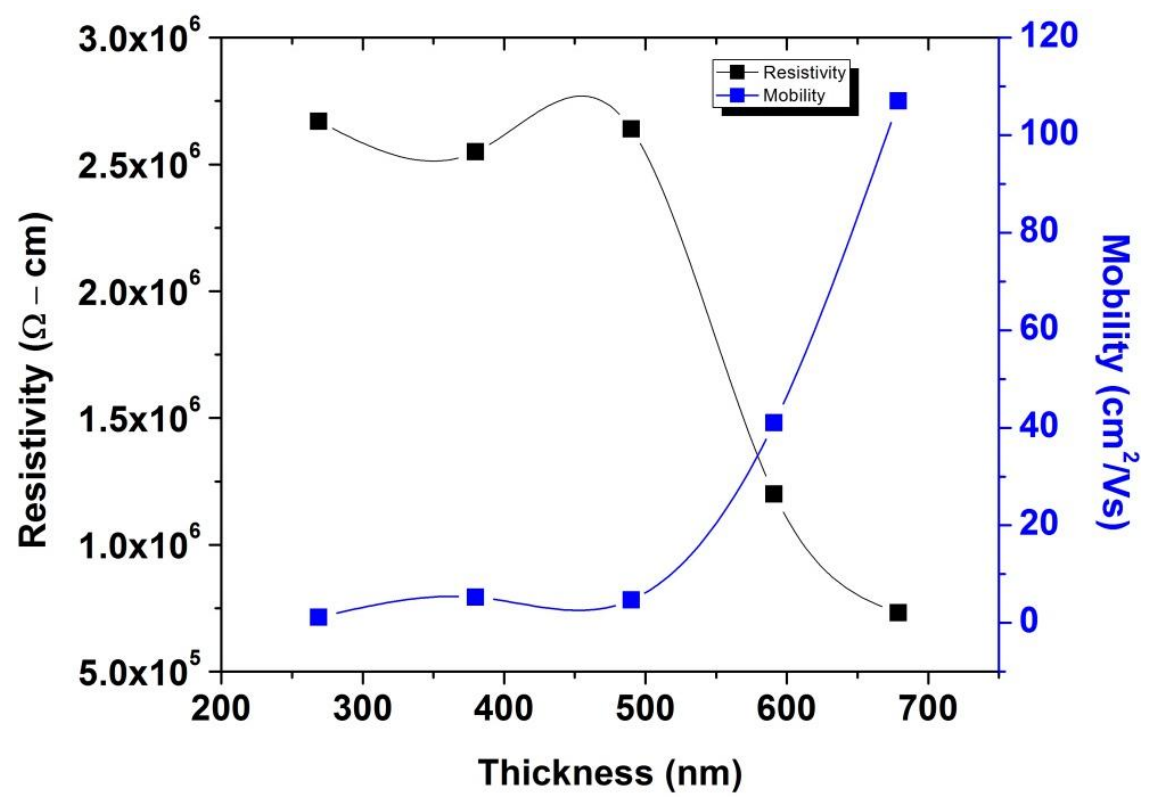

Figure 6 The resistivity and mobility of as grown thin films varied with increase in their thicknesses. Beyond a thickness of $500 \mathrm{~nm}$ both the resistivity and mobility changed $\sim 5$ and 100 times respectively. 


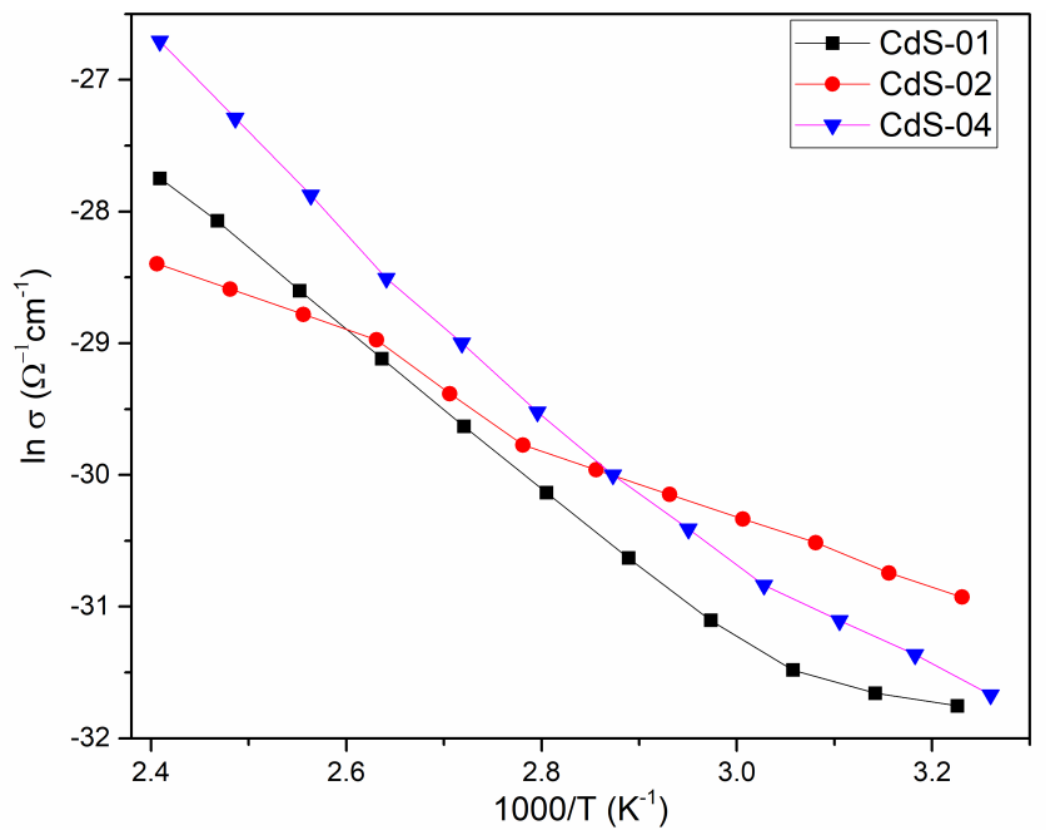

Figure 7 Arrhenius plot of thermal activation energy for as deposited $\mathrm{CdS}$ thin films at different dwell times. Activation energies change slightly with growth conditions 


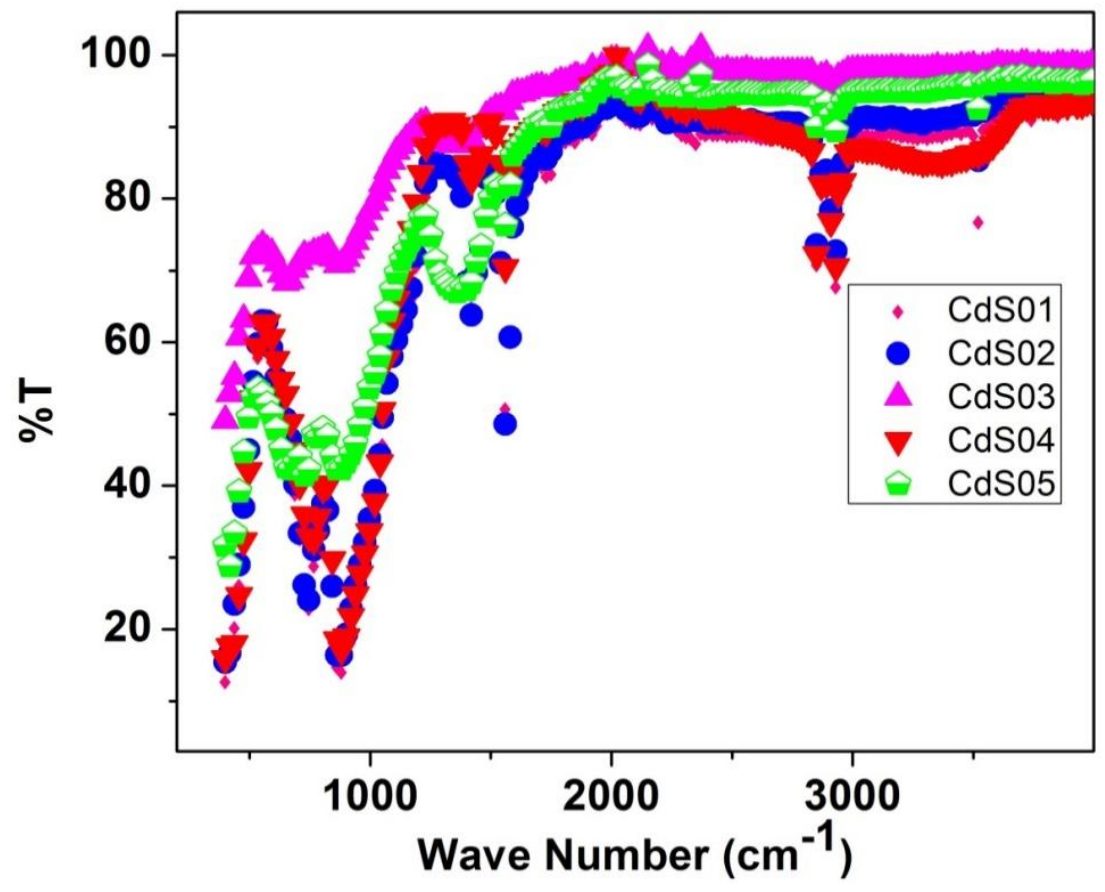

Figure 8 FT-IR Spectra of as-deposited CdS thin films 
Table 1: Crystallite size variation with Dwell time

\begin{tabular}{|l|l|l|l|}
\hline \multicolumn{1}{|c|}{ Sample } & \multicolumn{1}{|c|}{$\begin{array}{c}\text { Dwell time } \\
\text { (seconds) }\end{array}$} & Crystallite size (nm) & $\begin{array}{l}\text { Texture Coefficient } \\
\text { T.C. }\end{array}$ \\
\hline CdS-1 & 60 & $24.42 \pm 0.12$ & 3.31 \\
\hline CdS-2 & 200 & $27.69 \pm 0.14$ & 2.08 \\
\hline CdS-3 & 300 & $31.96 \pm 0.12$ & 1.74 \\
\hline CdS-4 & 400 & $27.70 \pm 0.17$ & 0.37 \\
\hline CdS-5 & 500 & $24.42 \pm 0.11$ & 0.37 \\
\hline & & & \\
\hline
\end{tabular}

